क्ष

\section{Heat Leak Performance of SSC Collider Dipole Magnets}

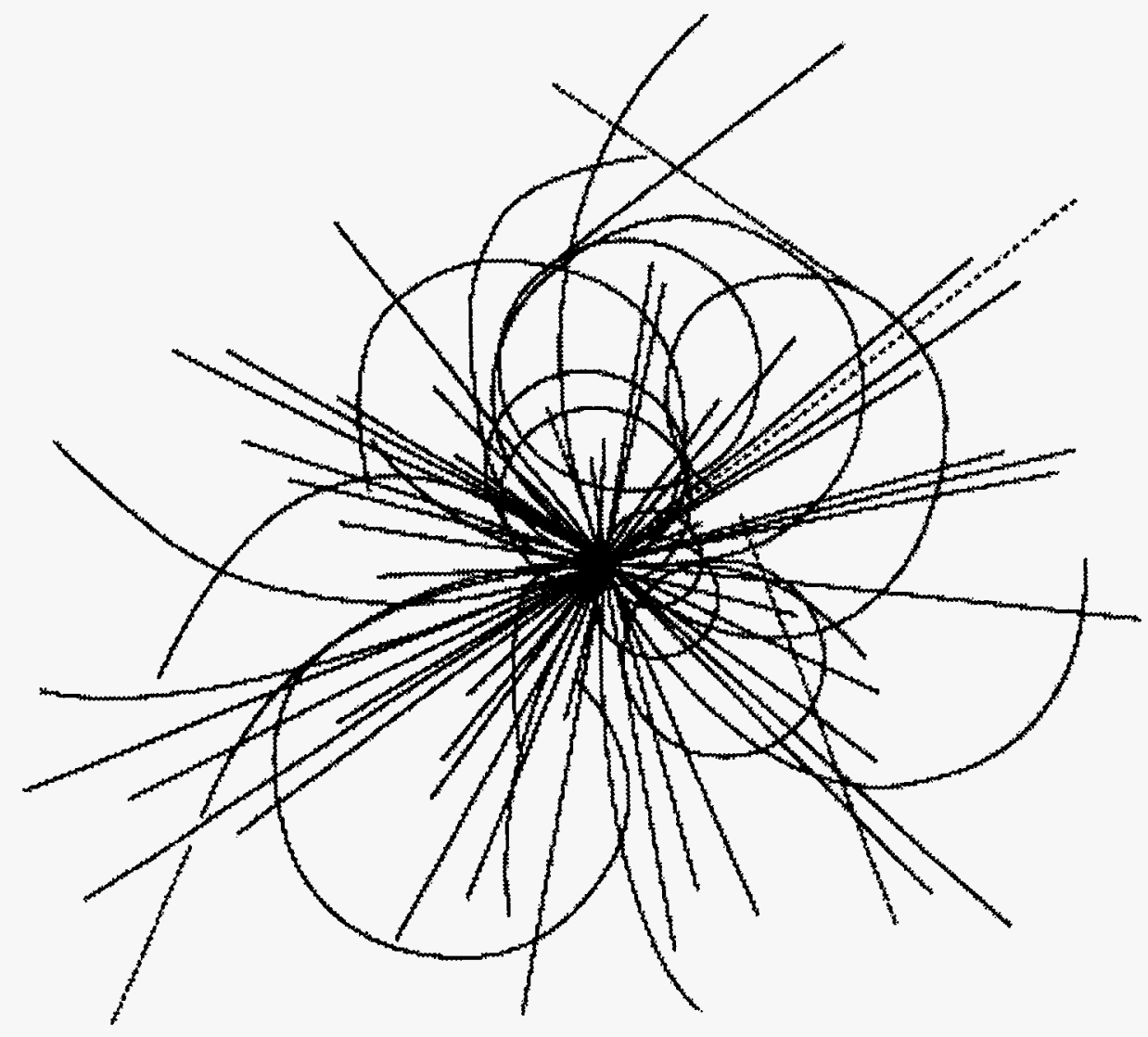

\section{Superconducting Super Collider Laboratory}

SSCL-Preprint-508

September 1993

Distribution Category: 414

J. Weisend II

M. Levin

D. Franks

R. Pletzer

S. Augustynowicz

A. McInturff

W. Boroski 


\section{Disclaimer Notice}

This report was prepared as an account of work sponsored by an agency of the United States Govemment. Neither the United States Government or any agency thereof, nor any of their employees, makes any warranty, express or implied, or assumes any legal liability or responslbility for the accuracy, completeness, or usefulness of any information, apparatus, product, or process disclosed, or represents that its use would not infringe privately owned rights. Reference herein to any speciffe commercial product, process, or service by trade name, trademark, manufacturer, or otherwise, does not necessarily constitute or imply its endorsement, recommendation, or favoring by the United States Government or any agency thereot. The views and opinions of authors expressed herein do not necessarily state or reflect those of the United States Govemment or any agency thereof. 


\section{DISCLAIMER}

Portions of this document may be illegible in electronic image products. Images are produced from the best available original document. 


\title{
Heat Leak Performance of SSC Collider Dipole Magnets*
}

\author{
J. Weisend II, M. Levin, D. Franks, et al. \\ Superconducting Super Collider Laboratory ${ }^{\dagger}$ \\ 2550 Beckleymeade Ave. \\ Dallas, TX 75237
}

September 1993

*Presented at the 13th Magnet Technology Conference, September 20th-24th, 1993; Victoria, British Columbia. †Operated by the Universities Research Association, Inc., for the U.S. Department of Energy under Contract No. DE-AC35-89ER40486. 
Heat Leak Performance of SSC Collider Dipole Magnets

J. G. Weisend II, M. Levin, D. Franks, R. Pletzer, S. Augustynowicz, A.D. McInturff, W. B. Boroski * SSC Laboratory, Dallas Tx., USA.

* Fermilab, Batavia, Il., USA.

\begin{abstract}
The large number of superconducting dipoles in the SSC results in a stringent heat leak budget for each dipole. Ensuring that the dipoles meet this budget is vital to the successful operation of the collider. This work surveys heat leak measurements taken during 4 different magnet string tests. These tests involved both $40 \mathrm{~mm}$ and $50 \mathrm{~mm}$ aperture dipoles. In these experiments the heat leak to the $80 \mathrm{~K}$ shield , $20 \mathrm{~K}$ shield and cold mass are measured. The results are compared to predictions from a computational thermal model of the dipole cryostat. Discrepancies are seen between the predicted and measured values. Possible explanations for these discrepancies are given.
\end{abstract}

\section{OVERVIEW}

The two collider rings of the SSC will contain approximately 8000 superconducting dipoles. In order to minimize the size of the required cryogenic plants the heat leak per dipole must be kept very low. Thus, a great deal of effort has been put into designing the cryostats for these magnets. The resulting design intercepts heat at three different levels: the $80 \mathrm{~K}$ shield, the $20 \mathrm{~K}$ shield and the $-4 \mathrm{~K}$ cold mass where the superconducting coils are located. Further details on the cryostat design may be found in [1]. Table I shows the budgeted static (as opposed to beam related) heat leak for each of the temperature levels in both the 40 and 50 $\mathrm{mm}$ aperture dipoles.

Table I

Collider Dipole Static Heat Leak Budgets (all values in Watts)

$\begin{array}{ccc} & 40 \mathrm{~mm} & 50 \mathrm{~mm} \\ 80 \mathrm{~K} & 27 & 37 \\ 20 \mathrm{~K} & 3.3 & 5.055 \\ \text { Cold Mass } & 0.28 & 0.363\end{array}$

Since 1990 a series of experiments have been conducted to measure the heat leak to each of these temperature levels in prototype full length $40 \mathrm{~mm}$ and 50 aperture dipoles. These experiments were all conducted as part of magnet string tests to minimize the impact of heat leaking into the dipoles from the ends.
The full length $40 \mathrm{~mm}$ aperture dipoles were measured at the ER string test conducted at Fermilab and the $50 \mathrm{~mm}$ aperture dipole tests were conducted as part of the Accelerator System String Test ( ASST) performed at the SSC Laboratory. Table II summarizes the parameters of these experiments.

By 1990 the decision had been made to go to $50 \mathrm{~mm}$ aperture dipoles. Nevertheless, heat leak measurements were made of the $40 \mathrm{~mm}$ aperture dipoles because it allowed the measurement technique to be tested before the $50 \mathrm{~mm}$ dipoles were available and because the 50 $\mathrm{mm}$ aperture dipole cryostat is an evolution of the 40 $\mathrm{mm}$ dipole cryostat.

Table II List of Heat Leak Experiments Performed

\begin{tabular}{|c|c|c|}
\hline Name & $\begin{array}{c}\text { Type of } \\
\text { Experiment }\end{array}$ & $\begin{array}{c}\text { Measurements } \\
\text { Performed }\end{array}$ \\
\hline ER Run \#1 & $\begin{array}{l}\text { 2 Dipole string } \\
40 \mathrm{~mm}\end{array}$ & $80 \mathrm{~K}, 20 \mathrm{~K}$ \\
\hline ER Run \#2 & $\begin{array}{c}5 \text { Dipole string } \\
40 \mathrm{~mm}\end{array}$ & $\begin{array}{c}80 \mathrm{~K}, 20 \mathrm{~K} \text {. } \\
\text { cold mass }\end{array}$ \\
\hline SST Run \#1 & $\begin{array}{l}5 \text { Dipole string } \\
50 \mathrm{~mm}\end{array}$ & $80 \mathrm{~K}$, cold mass \\
\hline ASST Run \#2 & $\begin{array}{l}5 \text { Dipole string } \\
50 \mathrm{~mm}\end{array}$ & $\begin{array}{l}80 \mathrm{~K}, 20 \mathrm{~K} \\
\text { cold mass }\end{array}$ \\
\hline
\end{tabular}

\section{EXPERIMENTAL METHOD}

In all cases the heat leak into a dipole was determined by measuring the temperature rise of the cryogen ( helium or nitrogen ) as it passes through the cold mass , $20 \mathrm{~K}$ shield cooling line or $80 \mathrm{~K}$ shield cooling line. Knowing this and the pressure of the fluid we can determine the rise in enthalpy of the fluid. Thus the heat leak into a dipole at a given temperature intercept is :

$$
q=\dot{m}\left(h_{\text {out }}-h_{\text {in }}\right)
$$

Where $m$ is the measured mass flow rate of the cryogen. Carbon glass resistors with an accuracy of $2.5 \mathrm{mK}$ were used at the inlet of each dipole's cold mass ( in the ER tests these sensors were also placed at the outlet of each dipole's cold mass ). Germanium resistors with an accuracy of $15 \mathrm{mK}$ were installed at the inlet and outlet of each dipole's $20 \mathrm{~K}$ shield cooling line. The $80 \mathrm{~K}$ shield cooling line contains platinum resistors with an accuracy of $0.5 \mathrm{~K}$ at the inlet and outlet of each dipole. 
All thermometers were directly immersed in the fluid flow. In the cold mass, $20 \mathrm{~K}$ and $80 \mathrm{~K}$ circuits of each dipole are resistive heaters with which a known amount of heat may be placed into the dipole as a test of the heat leak measuring technique. Warm pressure transducers are placed in each of the cryogenic pipes at the feed and end spools to determine the pressures of the flows. A Venturi meter measures the cold mass flow while room temperature volumetric gas meters measure the $20 \mathrm{~K}$ and $80 \mathrm{~K}$ flow rates. Figure 1 shows the instrumentation schematic of the ASST tests.

The heat leak measurements were made after

the strings were in thermal equilibrium. The measurements took place after string power tests were completed, typically after the string had been at helium temperatures for more than 4 weeks. In the measurements to date, the cold mass flow rate is kept at $\sim 50 \mathrm{~g} / \mathrm{s}$, the $20 \mathrm{~K}$ rate at $\sim 1$ to $2 \mathrm{~g} / \mathrm{s}$ and the $80 \mathrm{~K}$ rate at between 3 to $15 \mathrm{~g} / \mathrm{s}$. Due to these low flow rates the $80 \mathrm{~K}$ cooling flow tended to have a significant temperature rise across the strings. Thus, when we made measurements of the $20 \mathrm{~K}$ shield heat leak the $80 \mathrm{~K}$ circuit was filled with 2 phase $\mathrm{N}_{2}$ to ensure that the 80 $\mathrm{K}$ shield was uniformly at $\sim 80 \mathrm{~K}$.

\section{$40 \mathrm{~mm}$ RESULTS}

Table III summarizes the $20 \mathrm{~K}$ and $80 \mathrm{~K}$ shield measurements taken with the $40 \mathrm{~mm}$ full length dipoles at Fermilab.

\begin{tabular}{cccc} 
& \multicolumn{3}{c}{ Table III } \\
& Summary of & $40 \mathrm{~mm}$ Results \\
& DCA & DCA & DCA \\
& $17 / 26$ & 19 & 27 \\
$80 \mathrm{~K}$ & 18 & 36.2 & 22.5 \\
$+/-15 \%$ & $(32)$ & & \\
$20 \mathrm{~K}$ & 9.1 & & \\
$+/ 1 \%$ & $(10.1)$ & 5.6 & 6.7
\end{tabular}

DCA

201

27.5
The first ER test consisted of only 2 dipoles (\# 17 \& 26 ). To reduce the impact of heat leaking from the end of the string into the dipoles, the shield flow temperature sensors are placed in the middle of the dipoles so that by measuring the temperature rise from the middle of one dipole to the middle of the next, the heat leak to an effective dipole plus an interconnect is determined. This result is indicated as DCA 17/26 in Table III. The other dipoles in the 5 dipole string had thermometry in the inlet and outlet of each magnet.

The percent uncertainties listed with the $80 \mathrm{~K}$ and 20 $K$ results are based on a ratio of the temperature rises observed in each case with twice the absolute accuracy of the thermometers involved. Uncertainties in flow rate measurements and other system errors are measured by placing a known amount of heat into the cryogen flow via a resistance heater and comparing this known amount with the heat increase as measured by the thermometry. For the data shown here these uncertainties ranged between 10 and 20 percent.

Examining the data in Table III ( the 2 dipole test data are shown in parenthesis ) it is seen that with the exception of DCA 27 , all the $80 \mathrm{~K}$ shield heat leaks are greater than the budgeted value. Further, all the $20 \mathrm{~K}$ shield heat leaks are far greater than the budgeted value, in one case by as much as a factor of 3 .

Pressure measurements made during these tests did not indicate any problems with the isolation vacuum that could explain these higher than expected heat leaks. It is believed that the higher heat leaks are a result of thermal conduction between the $300 \mathrm{~K}$ wall and the 80 $\mathrm{K}$ shield, and the $80 \mathrm{~K}$ shield and the $20 \mathrm{~K}$ shield. Possible paths for this conduction include MLI blankets that were tightly pressed between the $300 \mathrm{~K}$ wall and the $80 \mathrm{~K}$ shield and between the $80 \mathrm{~K}$ shield and the $20 \mathrm{~K}$ shield as well as expansion joints on the shields that may act to short the shields and the $300 \mathrm{~K}$ wall together.

The results seen for the $20 \mathrm{~K}$ shield are consistent with measurements taken during an early test of a thermal model of the $40 \mathrm{~mm}$ cryostat [2]. In this test dhe additional heat leak was also attributed to conduction heat leak between the $20 \mathrm{~K}$ and $80 \mathrm{~K}$ shields.

In the 5 dipole experiment direct measurements were made of the shield temperatures using Cryogenic Linear Temperature Sensors bonded to the shields in several places. This measurement showed that the shield temperatures were within $3 \mathrm{~K}$ of the shield cooling flow temperature.

During the 5 dipole ER experiment, a measurement was made of the cold mass heat leak by measuring the temperature rise across the entire 5 dipoles. Calculating the heat leak associated with this rise and dividing by 5 the average cold mass heat leak is found to be $300 \mathrm{~mW}$ $+1-70 \%$. The uncertainty here being due mainly to the difficulty of maintaining a steady flow through the cold mass of the string. This measurement suggests that despite the problems with the shield heat leaks, the 40 $\mathrm{mm}$ cold mass heat leak comes very close to meeting its budget value of $280 \mathrm{~mW}$.

\section{$50 \mathrm{~mm}$ RESULTS}

The $50 \mathrm{~mm}$ dipole cryostats are very similar in design to the $40 \mathrm{~mm}$ cryostats. However, two significant changes to the thermal insulation system were made. The shield expansion joints, which were thought to be 
causing thermal shorts, were removed and greater care was taken in installing the MLI blankets in order to prevent them from causing thermal shorts. The results of the $50 \mathrm{~mm}$ tests are shown in Table IV. In both ASST experiments the order of the dipoles in the string is $313,314,319,315$, and 316 .

\begin{tabular}{ccccccc}
\multicolumn{8}{c}{ Table IV } \\
\multicolumn{8}{c}{ 50 mm Results } \\
( All Values in Watts ) \\
\multicolumn{8}{c}{ D313 } & D314 & D319 & D315 & D316 \\
Cold Mass & & & & & \\
20K & RUN 1 & 9.47 & 2.40 & 0.42 & 1.66 & 4.07 \\
& RUN 2 & 9.00 & 2.40 & - & 1.46 & 2.15 \\
80K & RUN 2 & 9.58 & 4.83 & - & 5.18 & 3.8 \\
& RUN 1 & 26.5 & 29.0 & 26.4 & 16.0 & 20.3 \\
& RUN 2 & 22.6. & 24.9 & 22.7 & 12.5 & 19.0
\end{tabular}

Comparing the results in Table IV with those from the $40 \mathrm{~mm}$ tests several significant differences stand out. In the case of the cold mass measurements the heat leak is far above the budgeted value unlike the $40 \mathrm{~mm}$ case.

Notice also the largest cold mass heat leaks are seen on the end magnets and that they get smaller as you move toward the middle of the string. This structure suggests that end effects may be present. End effects result from heat entering the string from the end travelling down the string and entering the cold mass space at some point in from the ends. One possible mechanism by which this may happen is that there may be regions of the end spools that are warmer than designed and these warm surfaces radiate heat down the vacuum space of the dipole cryostats. This heat is eventually deposited in the cold mass.

Another clue that end effects may be present is the change in measured heat leak in DCA 316 between Run 1 and Run 2. Note that the observed cold mass heat leak changes from 4.07 to $2.15 \mathrm{~W}$. No changes were made to the dipole between runs but, a major heat leak into the cold mass of the end spool which is close to DCA 316, was fixed. Thus, there is a strong correlation between the heat leak into the cold mass of the end spool and DCA 316.

It is not fully understood why end effects are present in these measurements and not in the $40 \mathrm{~mm}$ tests. The design of the end spools used in the $50 \mathrm{~mm}$ experiments is significantly different from the end cans used in the $40 \mathrm{~mm}$ experiments. It's highly possible that the spools have larger heat leaks than the end cans and contribute more to end effects.

In an attempt to reduce the end effects and th uncertainty in the measurements; the temperature rise across the middle three magnets is measured and an average per dipole plus interconnect for each temperature level is calculated. These results are shown in Table V.

Table V

Average Heat Leaks for $50 \mathrm{~mm}$ Dipoles (All Values in Watts )

$\begin{array}{cccc} & \text { Run 1 } & \text { Run 2 } & \text { Budget } \\ \text { Cold Mass } & 1.3 & 1.4 & \\ & +/-33 \% & +/-28 \% & 0.36 \\ 20 \mathrm{~K} & \text { N / A } & 5.59 & \\ & & /-2 \% & 5.06 \\ 80 \mathrm{~K} & 28 & 24.5 & 37\end{array}$

In the case of the $50 \mathrm{~mm}$ magnets the $20 \mathrm{~K}$ shield heat leak is very close to meeting the budget. This is a great improvement over the $40 \mathrm{~mm}$ cryostats where the $20 \mathrm{~K}$ heat leak was as much as three times over budget. The improvement is most likely a result of the removal of the shield expansion joints and better installation of the MLI blankets. These changes reduce the likelihood of thermal shorts between the $20 \mathrm{~K}$ and $80 \mathrm{~K}$ shields. Note also that the $80 \mathrm{~K}$ shield results are consistently within budget.

The uncertainties shown here reflect the absolute accuracy of the thermometry used. Tests made by placing a known heat load into the system and looking at the resulting temperature rise shown an uncertainty due to flow measurements and other system problems of less than $20 \%$.

A numerical model of the thermal performance of the ASST string has been developed [3]. This model is based on the cryostats being built exactly as designed. Using data from the second ASST run as input to the model, comparisons can be made between predicted and measured values of the heat leak. The predicted $80 \mathrm{~K}$ heat leaks are in good agreement with the measured values. The predicted $20 \mathrm{~K}$ results are lower than those measured. Thus, there may still be more thermal contact between the $20 \mathrm{~K}$ and $80 \mathrm{~K}$ shields then is allowed for in the ideal design. As expected, the thermal model predicts much lower values for the cold mass heat leak.

The obvious problem with the measurement technique used in these experiments is that it only provides a gross measurement of the cryostat heat leak. It does not tell us much about the cause of the additional aneak.

An attempt to remedy this problem is included in Run 3 of the ASST which is currently in operation. This string, composed of 10 dipoles and 2 quadrupoles, contains a highly instrumented dipole with thermal sensors on the 
shields, the support posts and the MLI blankets. It is expected that this will ascertain the causes of the cold mass heat leak or at least eliminate some of the likely candidates.

\section{CONCLUSIONS}

Dipole heat leak measurements have been underway as part of string testing since 1990. The techniques used have been shown to provide reliable measurements of the cryostat heat leak. Results of testing with full length $50 \mathrm{~mm}$ aperture dipoles show that the $80 \mathrm{~K}$ shield and $20 \mathrm{~K}$ shield meet their heat leak budget ( although the $20 \mathrm{~K}$ shield's heat leak is higher than predicted by computer models ). The cold mass heat leak observed is significantly higher than the budgeted amount. It is not clear at this time whether this is due to problems in the magnet cryostat itself or is an artifact of heat leaking from the end spools. Either way, changes in the dipole cryostat or the spool pieces will be necessary to fix the problem. As small adjustments in cryostat design tend to have large impacts in heat leak, it is not anticipated that radical design changes will be necessary in order for the dipoles to meet their design heat leak budget.

\section{ACKNOWLEDGMENT}

None of this work would have been possible without the assistance of large groups of technical professionals at Fermilab and the SSC. In particular, the authors wish to acknowledge the great contributions made by the installation and operation crews working under $\mathrm{C}$. White and M. Hentges, the cryogenic operations staff working under $G$. Mulholland, H. Carter and I. Urbin, and the controls group led by C. Dickey, D. Wallis, J. Zatopek and D. Haenni.

\section{REFERENCES}

[1] J. R. Sanford and D. M. Matthews (eds.) Site Specific Conceptual Design of the Superconducting Super Collider ( Report Number SSCL - SR - 1056, July, 1992).

[2] R. C. Niemann et al. "SSC dipole cryostat thermal model measurement results", Adv. Cryo. Engr. pp 251 258, New York, Plenum Press, 1987.

[3] D.E. Franks and R. K. Pletzer "The effect of vacuum pressures and species on internal heat leak in the SSCL magnet design", Supercollider $I V$, pp 267 274, New York, Plenum Press, 1992.

[4] A. McInturff, J. Weisend II, C. Dickey, R. Flora, and D. Wallis, "Measured control characteristics of the half cell $40 \mathrm{~mm}$ aperture magnet string", Supercollider $I$, pp 859 - 866, New York, Plenum Press, 1992.

[5] W. Burgett et al. , "Cyogenic characteristics of the SSC Accelerator Systems String Test ( ASST )", Presented at the Fifth International Industrial Symposium on the SSC, May, 1993.

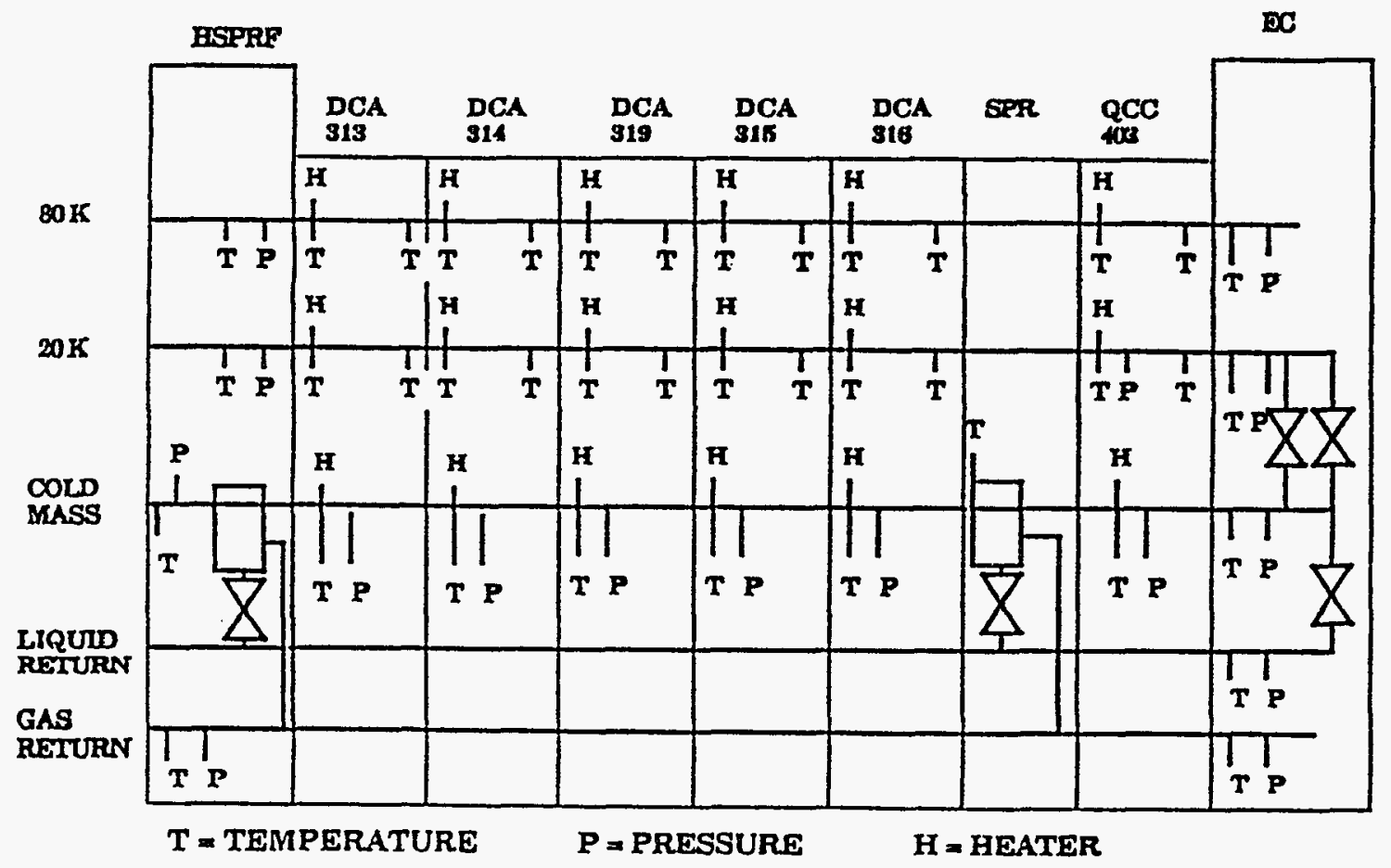

Fig.1. ASST Reduced Instrumentation Schematic. 